\title{
Characteristics of Aerosol Optical Thickness as Well as the Relationship with NDVI in the Yangtze River Delta, China
}

\author{
Zhongyong Xiao ${ }^{1}$, Hong Jiang ${ }^{2,3, *}$, Guomo Zhou ${ }^{3}$, Jian Chen ${ }^{3}$, and Renjian Zhang ${ }^{4}$ \\ ${ }^{1}$ School of Sciences, Jimei University, Xiamen, China \\ ${ }^{2}$ International Institute for Earth System Science, Nanjing University, Nanjing, China \\ ${ }^{3}$ Zhejiang Provincial Key Laboratory of Carbon Cycling in Forest Ecosystems and Carbon Sequestration, \\ Zhejiang Agriculture and Forestry University, Hangzhou, China \\ ${ }^{4}$ The Institute of Atmosphere Physics, Chinese Academy of Sciences, Beijing, China
}

Received 10 March 2012, accepted 2 May 2013

\begin{abstract}
A long term (2000 - 2008) dataset of aerosol products retrieved from MODerate Resolution Imaging Spectroradiometer (MODIS) is used to investigate the temporal and spatial variations of aerosol optical thickness (AOT) over the Yangtze River Delta (YRD). Ground-based observations (sun photometers) were used to validate the MODIS L2 aerosol products, and the Normalized Difference Vegetation Index (NDVI) derived from SPOT-VGT is used to analyze the relationship with AOT. The results illustrate that the highest correlation $(\mathrm{R}=0.92)$ of CE-318 AOT vs. MODIS AOT is in Hangzhou with the slope and intercept of 1.04 and -0.01 . The largest value of AOT appears in June, and has the largest spatial differences in July. There are two different aerosol patterns. One includes smaller AOT over dense vegetation cover areas dominated by natural aerosols and the other involves larger AOT over urban areas where anthropogenic aerosols dominate. The correlation analysis indicates that there are moderate negative correlation coefficients (R) for AOT vs. NDVI, and the R values vary as seasons shift. The range of $\mathrm{R}$ values is $0 \sim-0.8$ and the mean values are about -0.5 . The relationship between AOT and NDVI is more obvious in dense vegetation areas.
\end{abstract}

Key words: Aerosol optical thickness, Sun photometer, Yangtze River Delta, NDVI, MODIS

Citation: Xiao, Z., H. Jiang, G. Zhou, J. Chen, and R. Zhang, 2013: Characteristics of aerosol optical thickness as well as the relationship with NDVI in the Yangtze River Delta, China. Terr. Atmos. Ocean. Sci., 24, 863-876, doi: 10.3319/TAO.2013.05.02.01(A)

\section{INTRODUCTION}

Atmospheric aerosols play a significant role not only in human health but also in the Earth's climate. Aerosols critically affect the radiation budget in the atmosphere, and this effect contributes in two ways. First, aerosols scatter and absorb solar radiation, thus modifying the planetary albedo and reducing the radiation reaching the surface (Charlson et al. 1991, 1992). Second, aerosols as cloud condensation nuclei $(\mathrm{CCN})$ influence the microphysical properties of clouds and as a consequence their optical properties and atmospheric residence time change (Haywood and Boucher 2000). The net effect of aerosols is to cool the climate system by reflecting sunlight (Kaufman et al. 2002). However, these effects are quite uncertain (IPCC 2001, 2007) due mainly to the complicated physical and chemical properties of aerosols,

\footnotetext{
* Corresponding author

E-mail:jianghong_china@hotmail.com
}

their optical and radiative properties, and the lifetime of aerosols in the atmosphere.

As a crucial step toward the understanding of the complex effects of aerosols in the atmosphere, aerosol properties and distribution should be quantified accurately. Aerosol parameters can be measured in situ or by remote sensing from the ground and by satellite. Several aerosol groundbased observational networks have been established to understand aerosol optical properties such as NASA's Aerosol Robotic Network (AERONET) (Holben et al. 1998, 2001). AERONET provides much information on the properties of aerosols for global or regional research. In contrast to ground-based observations, space borne observations have the advantage of a global coverage. Recent instrument developments have offered new possibilities for measuring aerosol properties, such as the MODerate Resolution Imaging Spectroradiometer (MODIS) on NASA's Earth Observing 
System Terra and Aqua satellite platforms. MODIS is a useful sensor for aerosol properties study due to a higher spatial resolution and a near daily global coverage (Salomonson et al. 1989). The MODIS aerosol algorithm employs separate approaches to retrieve parameters over land (Kaufman et al. 1997) and ocean (Tanré et al. 1997; Levy et al.2007). Satellite remote sensing has provided a powerful means of assessing the distribution of aerosols over the world (King et al. 1999; Kaufman et al. 2002). However, the physical characteristics, composition, spatial and temporal distribution, as well as the variations of global aerosols are still not well known, and there are large uncertainties in remote sensing retrieval of aerosol properties. Therefore, a wide range of MODIS aerosol validation studies have been carried out using groundbased sun photometer measurements (Chu et al. 2002; Ichoku et al. 2002; Levy et al. 2005; Remer et al. 2005).

The wavelength dependence of the aerosol optical thickness (AOT) varies because of the aerosol type and their physical and chemical characteristics. This wavelength dependence is expressed by the Ångström exponent $(\alpha)$. Therefore, $\alpha$ is useful to distinguish and characterize different aerosol types (Eck et al. 1999; Cachorro et al. 2000). The dependence of $\alpha$ on AOT can be used to obtain the aerosol size distribution (d'Almeida 1987; Fouquart et al. 1987). Larger values of $\alpha$ indicate the prevalence of fine particles from urban industrial and biomass burning sources, while lower values of $\alpha$ are related to the presence of coarse particles such as desert dust and marine aerosols (Lyamani et al. 2006). The aerosol retrieval algorithm uses the vegetation index (Normalized Difference Vegetation Index, NDVI) to detect the dark pixels. Therefore, the aerosol retrieval is affected by the sensitivity of the vegetation index (King et al. 1999), particularly the new generation aerosol algorithm for MODIS introduced the NDVI of SWIR (Shortwave Infrared). In aerosol free conditions, NDVI of SWIR is highly correlated with NDVI (Levy et al. 2007). On the other hand, NDVI is a measure of the variation of land use and land cover (LULC). When there is no vegetation cover, soil dusts come from the dry surfaces under favorable atmospheric conditions (wind, relative humidity), suspending aerosols in the atmosphere (Kosmopoulos et al. 2008). Conversely, NDVI can be heavily influenced by aerosols (Tucker 1979), for NDVI values vary with absorption of red light by plant chlorophyll. NDVI is correlated with Intercepted Photo-synthetically Active Radiation (IPAR). In most cases (but not all) of IPAR and hence NDVI are correlated with photosynthesis, because photosynthesis occurs in the green parts of plants in the presence of solar radiation. Therefore, the vegetation condition sensitively changes with the sun's radiation variation (Tucker et al. 1985), and in turn the radiative forcing of aerosols can change the Earth radiation budget via scattering and absorbing the solar radiation (Charlson et al. 1991, 1992; IPCC 2001, 2007; Ramanathan et al. 2001). Generally, the higher the AOT is, the larger the aerosol radiative forcing. In that case, growth of vegetation will be constrained or promoted and results in the change of NDVI. Therefore, it is important to understand the relationship between aerosol properties and NDVI.

Urban areas contain rapidly changing in LULC. Urban aerosols are directly related to human activities and are gaining increasing attention (IPCC 2001; Ramanathan et al. 2001; Kaufman et al. 2002). The Yangtze River Delta (YRD) is a major industrial and commercial hub in China. Along with the fast economic development in the most recent two decades, dense aerosol loadings with diverse properties are emitted in this region, which provides a unique opportunity for understanding the impact of environmental changes on the climate system. The primary objective of this paper is to investigate the temporal and spatial variations of AOT. The secondary objective is to investigate the relationship between AOT and NDVI.

\section{DATA AND RESEARCH REGION}

\subsection{Data and Instruments}

MODIS aerosol products are useful for detailed studies of local, regional and global aerosol loading, distribution and temporal variations. MODIS flies on NASA's Earth Observing System Terra and Aqua satellite platforms. Terra and Aqua were launched on December 18, 1999 and May 4, 2002 with equator crossing times of approximately 10:30 and 13:30 EST respectively. The satellites are in a sun-synchronous, near polar, circular orbit. MODIS acquires data at 36 spectral bands, which range from the visible to the thermal infrared wavelengths. The spatial resolution varies from $250 \mathrm{~m}$ (bands 1 and 2), $500 \mathrm{~m}$ (bands $3-7$ ) and $1000 \mathrm{~m}$ (bands 8 - 36). The swath width of MODIS is about $2300 \mathrm{~km}$ with the field of view angle of $110^{\circ}$. AOT at $550 \mathrm{~nm}$ from MODIS Level 2 collection 5 aerosol products (MOD04) is used in this paper. Retrieved AOT over land surfaces is applied using the dark, dense vegetation (DDV) method (Kaufman et al. 1997). They are available nearly globally over land at a spatial resolution of $10 \mathrm{~km}$ at the nadir from the NASA's GSFC DAAC (http://ladsweb.nascom.nasa.gov/data/search. $\underline{\mathrm{html}}$ ). The satellite typically passes over the YRD between 10:00 and 12:00 EST each day. The time span of datasets used in the paper is from February 2000 to June 2009. In order to analyze the temporal and spatial variations of AOT, the data is integrated to monthly averages due to the lack of daily data for the most area in this region.

To assess the quality of MODIS Level 2 aerosol products, six Cimel sun photometers (CE-318 sun/sky scanning spectral radiometer) for ground-based measurements were installed in YRD region since 2007. The instruments measure direct sun light within a $1.2^{\circ}$ full field of view every $15 \mathrm{~min}$ utes at $340,380,440,500,675,870,940,1020$ and $1640 \mathrm{~nm}$. Measurements at $940 \mathrm{~nm}$ are used to derive water vapor column amount (Holben et al. 1998). These measurements 
can be used to derive AOT, aerosol size distribution and phase function. Information on the locations of the instruments and nearby cities in the YRD is shown in Table 1 and Fig. 1. The points for the comparison in Table 1 are based on the collocations number of MODIS and sun photometers (CE-318).

The NDVI has become one of the most widely used indices routinely derived from Advanced Very High Resolution Radiometer (AVHRR) images since 1981. Now, NDVI data canbederived from several sensors, including SPOT,AVHRR and MODIS. The NDVI data used in this paper come from the SPOT-VGT NDVI dataset that is a 10-day composite at $1 \times 1 \mathrm{~km}$ spatial resolution. The SPOT-VGT NDVI dataset was obtained from the website (http://www.vgt.vito.be) of VITO Belgium which flies on the SPOT satellite. The SPOT satellites (SPOT-4 and -5) are a high resolution, optical imaging Earth observation satellite system. The orbit is polar with an altitude of $832 \mathrm{~km}$, an inclination of $98.7^{\circ}$, and

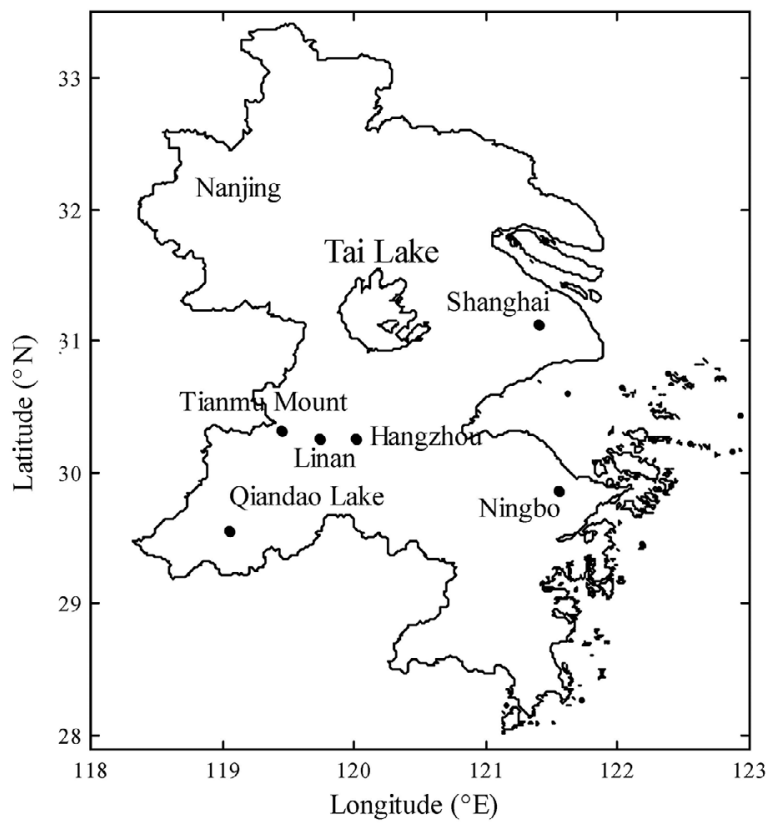

Fig. 1. Distribution of instruments and cities in the Yangtze River Delta. is circular and sun-synchronous with an equatorial crossing at 10:30 AM. The inclination of the orbital plane combined with the rotation of the Earth around the polar axis allows the satellite to fly over any point on Earth within 26 days. To match the resolution $(10 \times 10 \mathrm{~km})$ of MODIS aerosol products, the mean monthly NDVI data were resampled.

\subsection{Research Region}

The YRD is situated in the lower reaches of the Yangtze River in East China. The geographical coordinates are about $117.9^{\circ} \sim 123.5^{\circ} \mathrm{E}$ and $27.8^{\circ} \sim 33.6^{\circ} \mathrm{N}$. This region is affected by the marine and continental monsoons in the summer and winter, respectively. Therefore, the YRD has a marine monsoon subtropical climate, and the weather is hot and humid in the summer and cool and dry in winter. The YRD region is a major industrial and commercial hub in China. The urban development in the region has given rise to one of the largest concentrations of adjacent metropolitan areas in the world. It covers an area of $99600 \mathrm{~km}^{2}$ and is home to over 80 million people as of 2007, of which an estimated 50 million are urban. Along with the fast economic development in the most recent two decades, the region is experiencing rapid environmental changes. With expanding anthropogenic activity and urbanization, and fast growing industry, aerosol loading in YRD region has become increasingly dense. These pollutants may, therefore, provide a unique opportunity for understanding the impact of anthropogenic aerosol on the climate system, especially in urban regions.

\section{RESULTS AND DISCUSSION}

\subsection{Validation of MODIS Aerosol Products}

Inter-comparison and validation of aerosol products retrieved from satellite remote sensing is necessary. Many studies have been carried out to validate the MODIS aerosol products using ground-based sun photometer observations (Holben et al. 1998, 2001; Chu et al. 2002; Levy et al. 2005, 2007, 2010; Remer et al. 2005). Most of these validations have shown that MODIS AOT values were within the ex-

Table 1. Instruments and the collocation number (ND) of ground-based measurements and MODIS retrieval.

\begin{tabular}{lcccccc}
\hline Site Name & Longitude $\left({ }^{\circ} \mathbf{E}\right)$ & Latitude $\left({ }^{\circ} \mathbf{N}\right)$ & Height $(\mathbf{m})$ & Name & Time & ND \\
\hline Hangzhou & 120.01 & 30.263 & 24 & 458 & $2008-04 \sim 2009-06$ & 74 \\
Linan & 119.73 & 30.257 & 89 & 378 & $2007-10 \sim 2009-06$ & 102 \\
Ningbo & 121.55 & 29.86 & 24 & 379 & $2007-08 \sim 2008-08$ & 32 \\
Qiandao Lake & 119.05 & 29.55 & 125 & 376 & $2008-03 \sim 2009-06$ & 88 \\
Shanghai & 121.4 & 31.13 & 49 & 377 & $2008-03 \sim 2009-06$ & 30 \\
Tianmu Mount & 119.44 & 30.324 & 439 & 457 & $2007-10 \sim 2009-06$ & 95 \\
\hline
\end{tabular}


pected error. However, the lower AOT values were overestimated and the higher AOT values were underestimated (Chu et al. 2002; Levy et al. 2005; Remer et al. 2005). The accuracy of the MODIS aerosol products is still uncertain for use in the YRD due to a lack of validation by long term and large scale ground-based observations (Wang et al. 2007). In this paper, AOT from MODIS at $550 \mathrm{~nm}$ is being validated using ground-based observation data (sun photometer). The matching AOT values at $550 \mathrm{~nm}$ of the sun photometer were derived by interpolation based on the Angström law (Ångström 1929) using AOT at wavelengths of 440, 500 and $675 \mathrm{~nm}$ because the sun photometer does not measure $\mathrm{AOT}$ at $550 \mathrm{~nm}$. Data from the sun photometer is measured within \pm 30 min of MODIS satellite overpass time (Ichoku et al. 2002), and the MODIS AOT were averaged over a 3 by 3 pixels area centered at the ground stations. The total number of point is shown in the Table 2 .

The linear regression analysis of ground versus satellite AOT is shown in Fig. 2, and the corresponding parameters are presented in Table 2 . The results illustrate that higher correlations are in the cities of Hangzhou, Linan, Ningbo, Qiandao Lake and Shanghai with R equal 0.92, 0.83, 0.85, 0.78 and 0.78 , respectively. There appears to be a moderate correlation in the area of Tianmu Mountain with R equal to 0.61 . As shown in the figure, the MODIS retrieval results have considerable uncertainties. The slopes and intercepts of the regression are much different with the values varying from 0.41 to 1.20 and from -0.17 to 0.50 , respectively. Compared with the global validation with 0.9 and 0.1 of the slope and intercept (Levy et al. 2007), these local

Table 2. Statistical values for the evaluation of the MODIS AOT with that of the sun photometer, including slope, intercept, correlation coefficient (R), root mean square errors (RSME) and the collocation number (ND).

\begin{tabular}{lccccc}
\hline Site Name & Slope & Intercept & R & RSME & ND \\
\hline Hangzhou & 1.04 & -0.01 & 0.92 & 0.20 & 74 \\
Linan & 0.92 & -0.15 & 0.83 & 0.21 & 102 \\
Ningbo & 1.20 & 0.02 & 0.85 & 0.21 & 32 \\
Qiandao Lake & 1.01 & -0.17 & 0.78 & 0.20 & 88 \\
Shanghai & 0.82 & 0.50 & 0.78 & 0.24 & 30 \\
Tianmu Mount & 0.41 & 0.09 & 0.61 & 0.22 & 95 \\
\hline
\end{tabular}

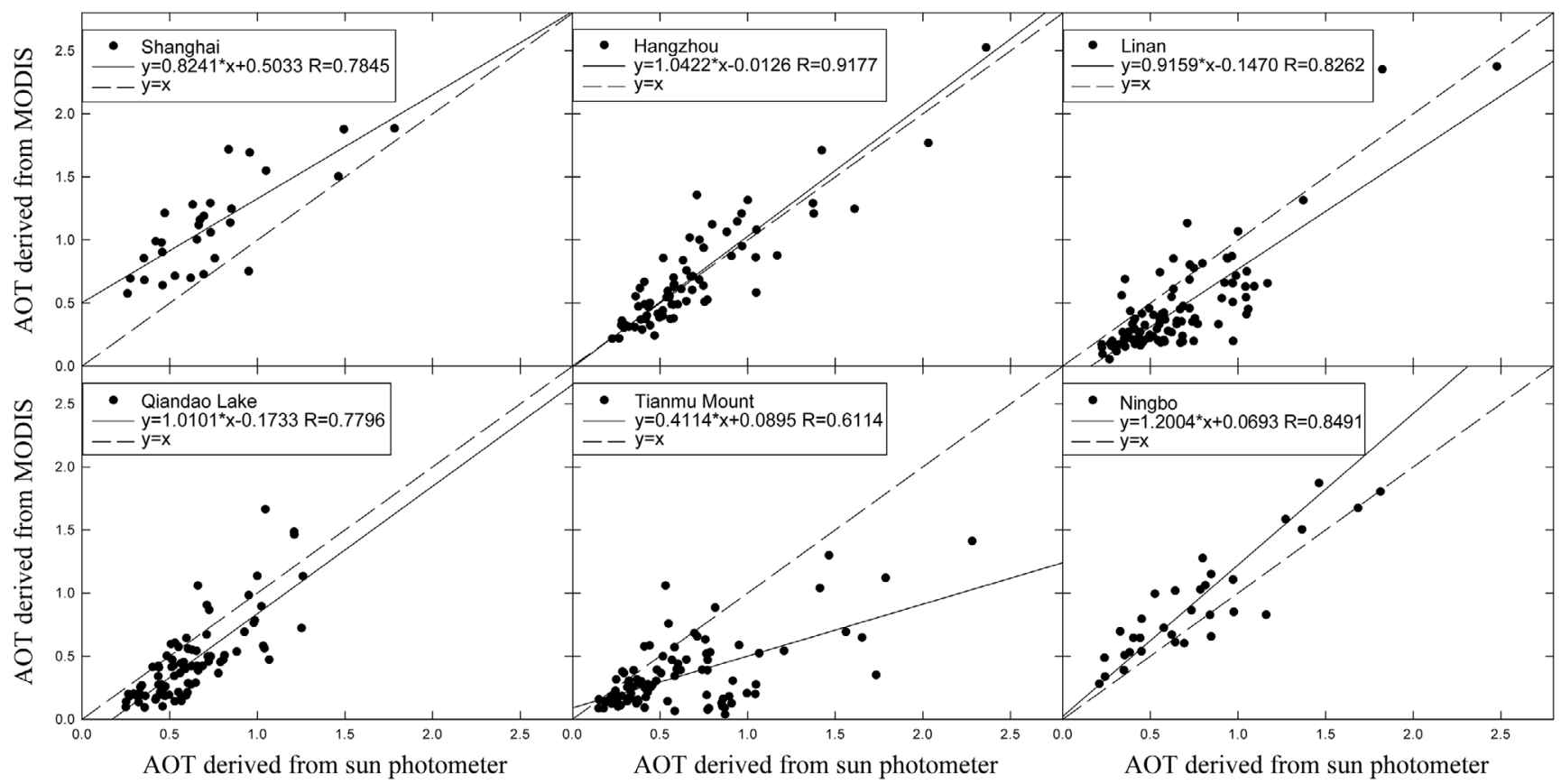

Fig. 2. Scatter plots the AOTs from ground-based measurements (sun photometer) and satellite retrieved (MODIS) in 6 collocation sites, and the regression analysis are performed. An identical scale in the $\mathrm{x}$ and $\mathrm{y}$ axes is used in order to show the difference of relation among these sites. 
monitoring results are more uncertain. The Shanghai station has an overestimation of MODIS AOT. In the Linan, Qiandao Lake and Tianmu Mountain stations, the MODIS AOT is generally an underestimation. At the Hangzhou station, the MODIS AOT is in good agreement with groundbased measurements, the slope and intercept are 1.04 and -0.01 with $\mathrm{R}$ and RMSE equal to 0.92 and 0.20 respectively. At the Ningbo station, the MODIS AOT is generally an overestimation with the slope and intercept of 1.20 and 0.02 respectively, while it has a higher $\mathrm{R}$ of 0.85 . The validation studies show that MODIS AOT has a larger error in this region. Some of observations are good, such as Hangzhou, Ningbo, and agree well with other research results (Ichoku et al. 2004; Levy et al. 2005, 2010). The possible explanations for the uncertainty of MODIS AOT are due to inaccuracies in the surface reflectance assumptions and other properties inaccurate assumptions in the aerosol models. The complicated meteorological conditions (such as wind, precipitation and cloud) also contributed to the larger error (Kim et al. 2007), and the time-space matching for the linear regression of scattering points also contributed to the uncertainty in this region.

\subsection{Characteristics and Variability of Aerosol Optical Thickness}

Growing anthropogenic activities due to rapid industrialization and urbanization in the YRD have led to increase in aerosol loading. The temporal evolution of AOT was described in 3 respects; first is the temporal variation of regional monthly average AOT; second is the seasonal characteristics of regional monthly average AOT; and, the last is the characteristics of monthly average AOT in five representative cities.

\subsubsection{The Temporal Variation of Regional Monthly Average AOT}

In order to investigate the variation of aerosol loading in this region, the variation of AOT is used in the following analysis. Figure 3 shows the time series of regional monthly mean AOT with standard deviation at $550 \mathrm{~nm}$ derived from the MODIS/Terra aerosol data covering the 9 years from February 2000 to December 2008. The standard deviation is calculated using the monthly means of all the pixels within the entire region which portray the spatial difference of regional AOT. The AOT presents an obvious annual cycle, and shows a marked seasonal variation in the monthly average AOT. The largest value often appears in May or June, and the smallest often appears in December or January. In short, the AOT is getting larger over the entire region). The spatial difference is also getting larger due to the AOT over urban areas is increasing faster than those of in rural areas. This increase is usually caused by the human activity associated with anthropogenic pollutants, which are more apparent in urban areas. Also one can note that the standard deviation values in May or June are larger than that in December or January. This implies that the spatial differences in May or June are larger than those in December or January.

\subsubsection{The Seasonal Characteristics of Regional Average AOT}

In the paper, seasons are divided into spring (March, April and May, MAM), summer (June, July and August, JJA), autumn (September, October and November, SON) and winter (December, January and February, DJF). Figure 4 plots the temporal variation of the regional monthly mean AOT over YRD region during 2000 to 2008. The AOT exhibits distinct seasonal variation. This implies a seasonal

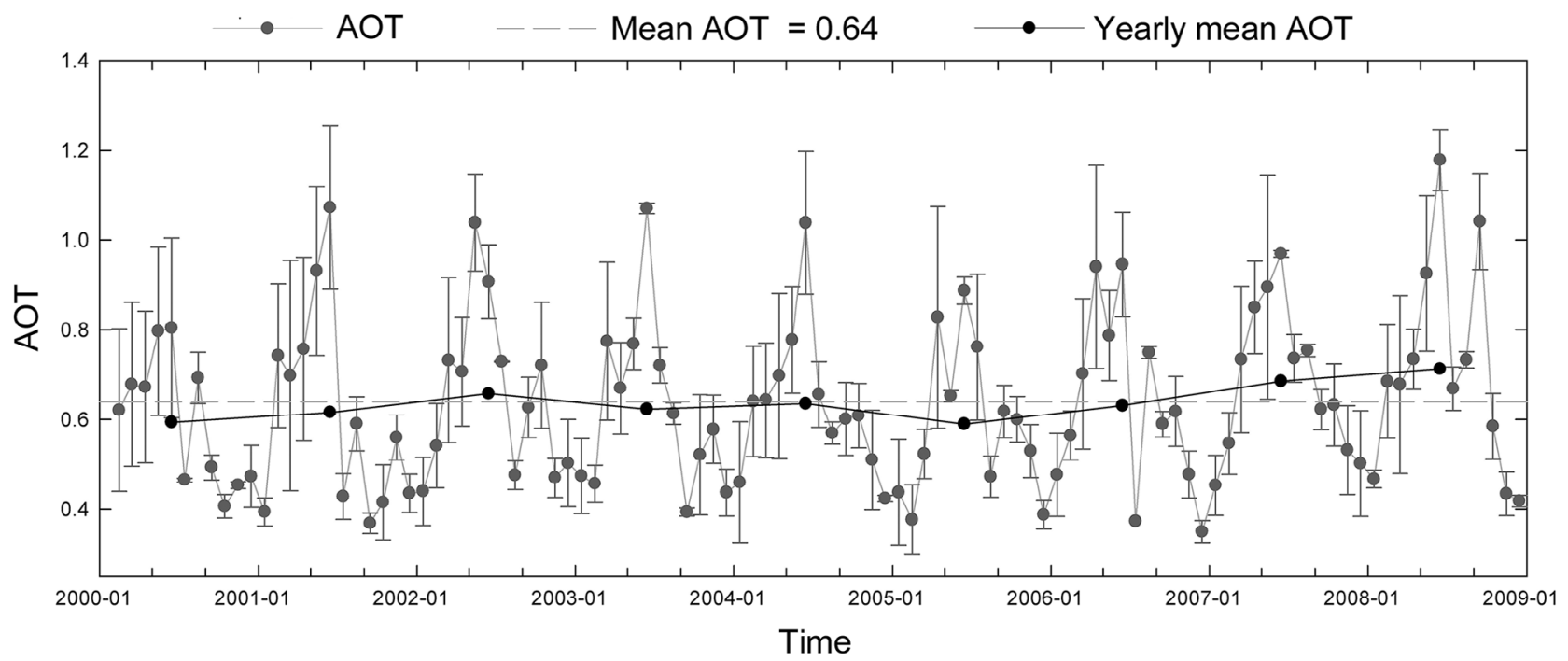

Fig. 3. Variation of regional monthly mean AOT with standard deviation over the Yangtze River Delta. 

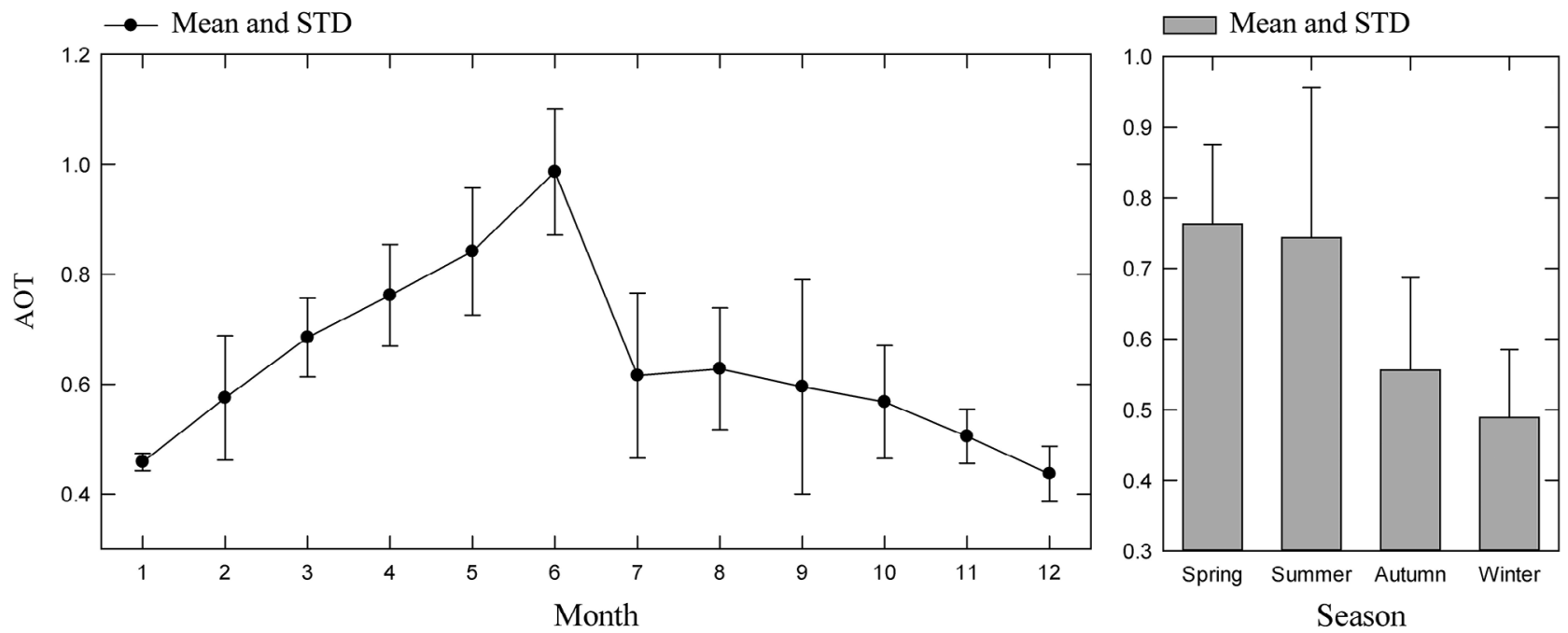

Fig. 4. The regional monthly and seasonal means AOT $(550 \mathrm{~nm})$ with standard deviation (STD) over the Yangtze River Delta.

shifting in aerosol type. The largest value of AOT $(0.99 \pm$ 0.11 ) appears in June, and has a larger standard deviation. The AOT value jumps to $0.62 \pm 0.15$ from $0.99 \pm 0.11$ of June to July. The reason is likely due to the plum rains washing away partial aerosol particles over the whole region. The spatial difference of AOT $(0.46 \pm 0.02)$ over this region is smallest (standard deviation $=0.02$ ). The smallest values of AOT are in December $(0.44 \pm 0.05)$ and April $(0.75 \pm 0.09)$, respectively. The AOTs have a distinct monthly variability due primarily to the complex aerosol types in this region, such as sea-salt aerosols, anthropogenic aerosols from industrial activity, and biomass burning aerosols from rice straw burning during summer and autumn. This variation also implies the changing of aerosol types. There is an increase in small aerosol particles due to the biomass burning aerosol in summer and autumn. In the spring and winter seasons, larger continental/dust aerosol particles dominate in this region, because of the effect of the continental monsoon.

\subsubsection{Characteristics of Monthly Average AOT in Dif- ferent Representative Cities}

The AOTs of the representative cities are analyzed in this section. Figure 5 maps the spatial distribution of multi-year mean AOT, and shows the locations of five representative cities in the YRD which include Qiandao Lake $\left(119.05^{\circ} \mathrm{E}, 29.58^{\circ} \mathrm{N}\right)$, Ningbo $\left(121.55^{\circ} \mathrm{E}, 29.90^{\circ} \mathrm{N}\right)$, Hangzhou $\left(120.15^{\circ} \mathrm{E}, 30.25^{\circ} \mathrm{N}\right)$, Shanghai $\left(121.45^{\circ} \mathrm{E}, 31.10^{\circ} \mathrm{N}\right)$, and Nanjing $\left(118.80^{\circ} \mathrm{E}, 32.00^{\circ} \mathrm{N}\right)$. These areas are situated in regions having different AOT values.

The typical temporal variation of the principal aerosol types can be appreciated by examining the characteristics of AOT over these five representative cities (Fig. 6). The common situation is that the AOT values over these areas are increasing with time especially in urban areas; the in- crease of AOT is implicit. Growing anthropogenic activities due to rapid industrialization in the YRD region have led to increased aerosol loading, and make the aerosol size distributions more complex with mixtures of pollutants, mineral aerosols and smoke aerosols (Xin et al. 2007). The change of LULC as well as wind and other meteorological conditions contribute to the regional discrepancy. The magnitudes of both AOTs can be divided into two types of natural and anthropogenic aerosols. The AOT values of Qiandao Lake are less than other areas because the clean air makes the

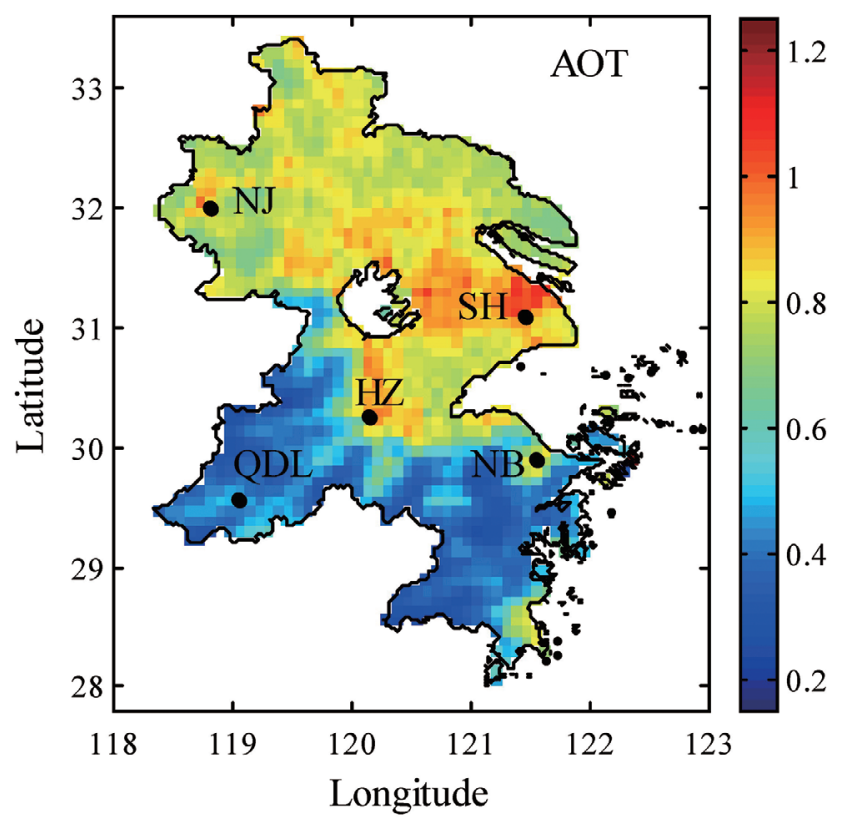

Fig. 5. Maps of multi-year mean AOT $(550 \mathrm{~nm})$, and the locations of the five representative cities, the NJ, SH, HZ, QDL and NB stand for the city of Nanjing, Shanghai, Hangzhou, Qiandao Lake and Ningbo, respectively. 


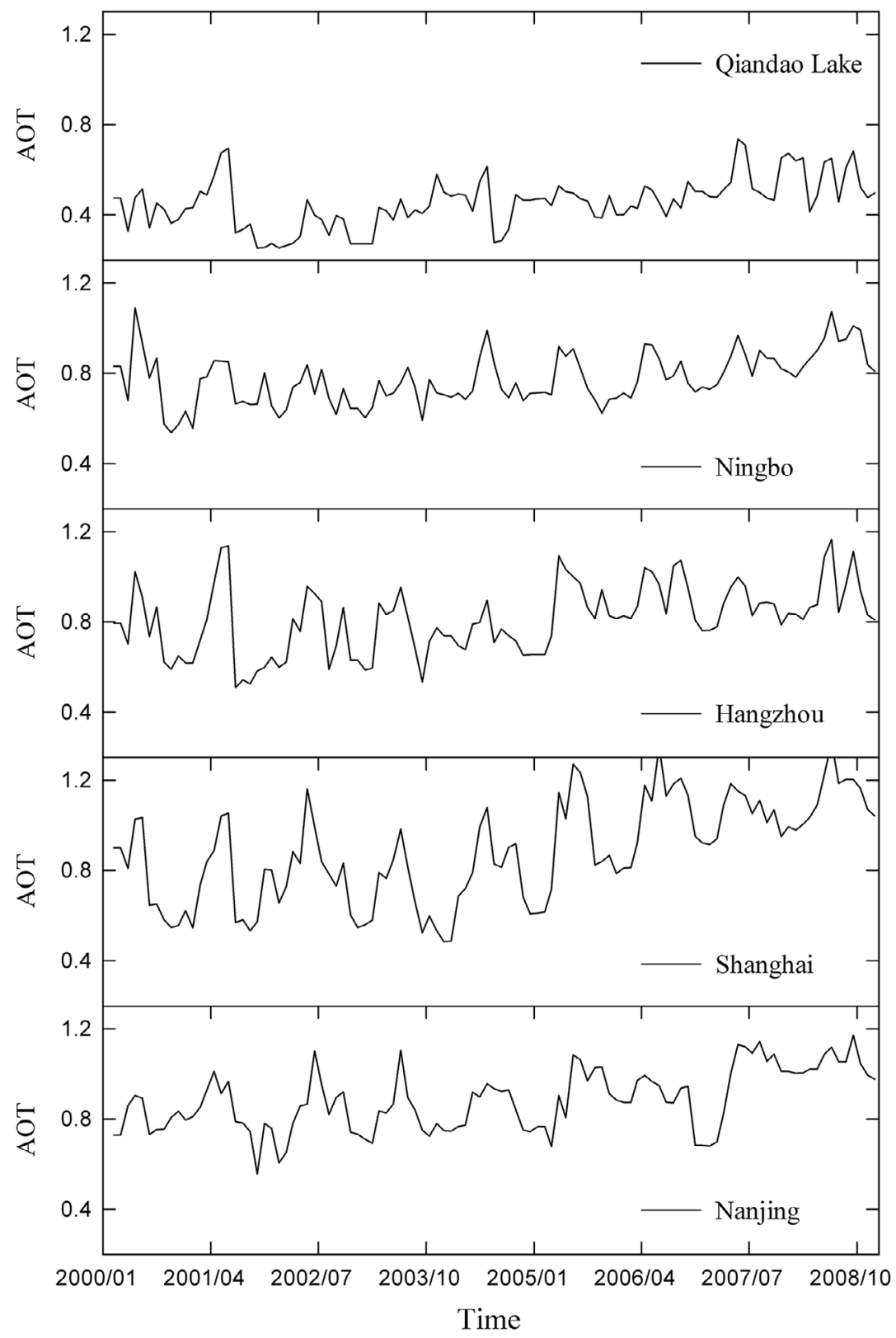

Fig. 6. Variations of monthly mean AOT over the five representative cities.

annual mean AOT low ranging from 0.37 to 0.55 . In urban areas, the annual mean AOT ranges from 0.68 to 0.92 . The results indicate that the AOT is larger for the anthropogenic aerosols than natural aerosols.

There are two different modes for aerosol in these five cities. One mode has a small AOT over Qiandao Lake with dense and homogeneous vegetation cover wherein aerosol types are relatively stable. The multi-year averaged AOT is $0.45 \pm 0.11$. The atmosphere at Qiandao Lake is the cleanest among all these areas studied here. The reason may be the higher relative humidity around Qiandao Lake, because water vapor can affect aerosol properties. Research has suggested that there is a clear positive correlation between water vapor content and AOT (Eck et al. 2001; Smirnov et al. 2002; Kaskaoutis et al. 2006). Therefore, some of the increase in aerosol particles may be the result of absorption by water vapor. The AOTs over other urban regions are similar. The values of AOT are larger, and the values are $0.77 \pm$ $0.11,0.81 \pm 0.15,0.88 \pm 0.23$ and $0.88 \pm 0.14$ for Ningbo, Hangzhou, Shanghai and Nanjing respectively; the reason is due mainly to the effect of the anthropogenic industrial/ urban aerosol types over these areas.

\subsection{Spatial Distribution of Aerosol Optical Thickness}

Figure 7 maps the spatial distribution of the multi-year 

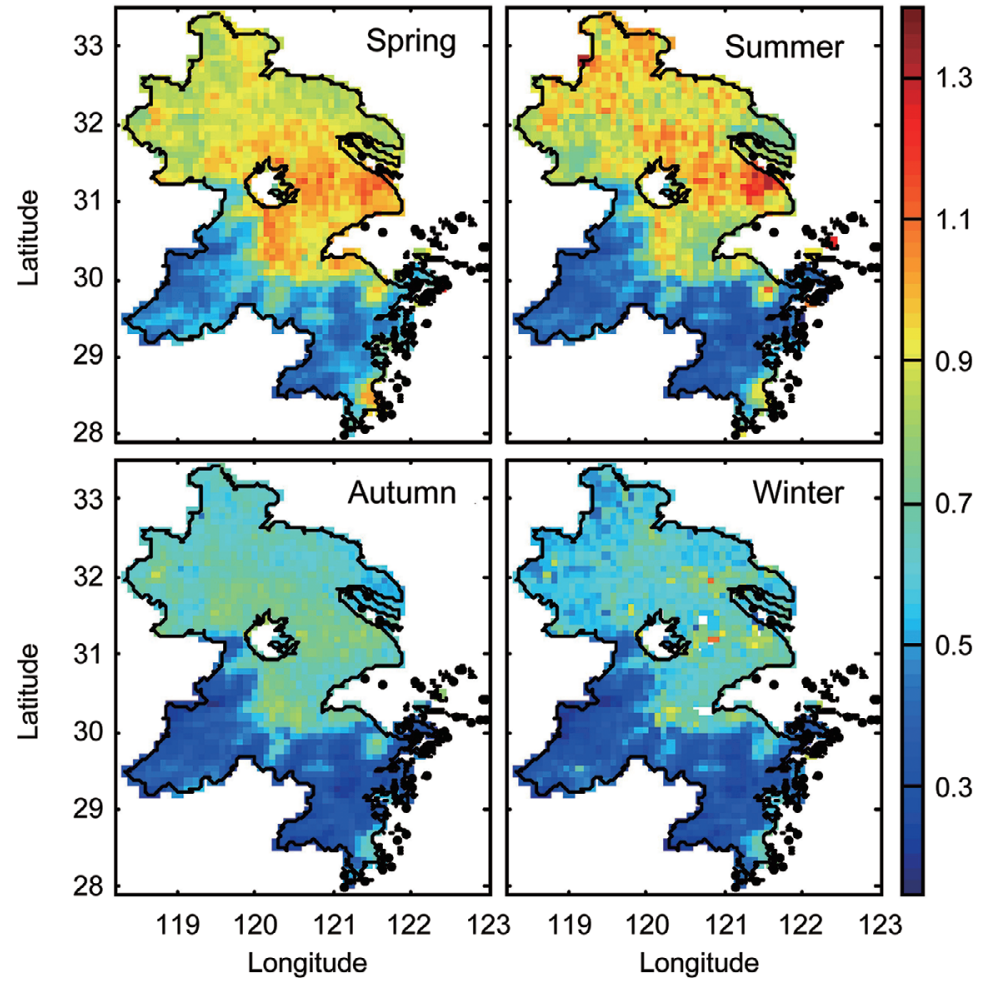

Fig. 7. Spatial distributions of multi-year seasonal mean AOT from 2000 to 2008 over the Yangtze River Delta.

seasonal mean AOT over the YRD region. The AOTs in the urban regions are larger than those in rural regions with clean air and dense vegetation. The AOT is largest over Shanghai and other cities around Tai Lake, where drastic human activity takes place. Spring has the largest regional mean AOT of $0.77 \pm 0.21$. The summer AOT of $0.73 \pm 0.25$ is lower than that of spring, but has a larger standard deviation. Therefore, it has a more distinct spatial difference. The AOTs of summer are larger than those of spring in urban areas, vise versa. It is likely due to the warm and moist season which favors the accumulation of urban aerosols (Adamopoulos et al. 2007; Kosmopoulos et al. 2008). Moreover, the higher AOTs in urban areas in summer can be attributed to the relative contribution of various processes such as stagnant synoptic meteorological fields, secondary photochemical aerosol formation, hygroscopic growth of water soluble industrial aerosols and biomass smoke from seasonal biomass burning from rice straw burning. In dense vegetation, the water soluble industrial aerosols are less. Then the hygroscopic effect on AOT values is not so obvious. As shown in the Fig. 7, the largest values appear over Shanghai, and the smallest appear over the southern YRD region for the year round. This pattern highlights the difference between urban areas with sparse vegetation and the rural areas with dense vegetation, that is, the dominance by the anthropogenic and natural aerosol types, respectively. Winter has the smallest AOT $(0.52 \pm 0.15)$ with a standard deviation of 0.15 . Hence, the smallest spatial variation of vegetation has an influence on the spatial distribution of AOT. Figure 8 maps the spatial distribution of annual mean AOT over the YRD region from 2000 to 2008. The AOT is clearly increasing over time in the entire region, especially in the urban areas around the Tai Lake. Table 3 shows that areas of lower AOT decreased, while areas of larger AOT increased from 2000 to 2008. The area of AOT less than 0.4 , and between 0.4 and 0.8 , respectively accounted for $20.80 \%$ and $68.59 \%$ in 2000 , and they decreased to $10.55 \%$ and $45.80 \%$ in 2008 over this region. Meanwhile, the area of AOT larger than 0.8 accounted for $10.61 \%$ in 2000 , and increased to $43.65 \%$ in 2008 . This may result from the urbanization of the region. Rapid industrial development and human activity increase aerosol emissions especially sulphate aerosols in the east coast of China.

\subsection{The Relationship Between AOT and NDVI}

\subsubsection{Spatial Distribution of NDVI}

NDVI is affected significantly by seasonal variation. Therefore, we divided the data into different seasons to analyze the spatial characteristics of NDVI to better understand the relationship with aerosol properties. Figure 9 maps the spatial distribution of multi-year (2000 - 2008) seasonal mean NDVI in different seasons over the YRD region. A distinct spatial pattern emerges in the NDVI values which vary as the seasons shift, for the vegetation in this region 

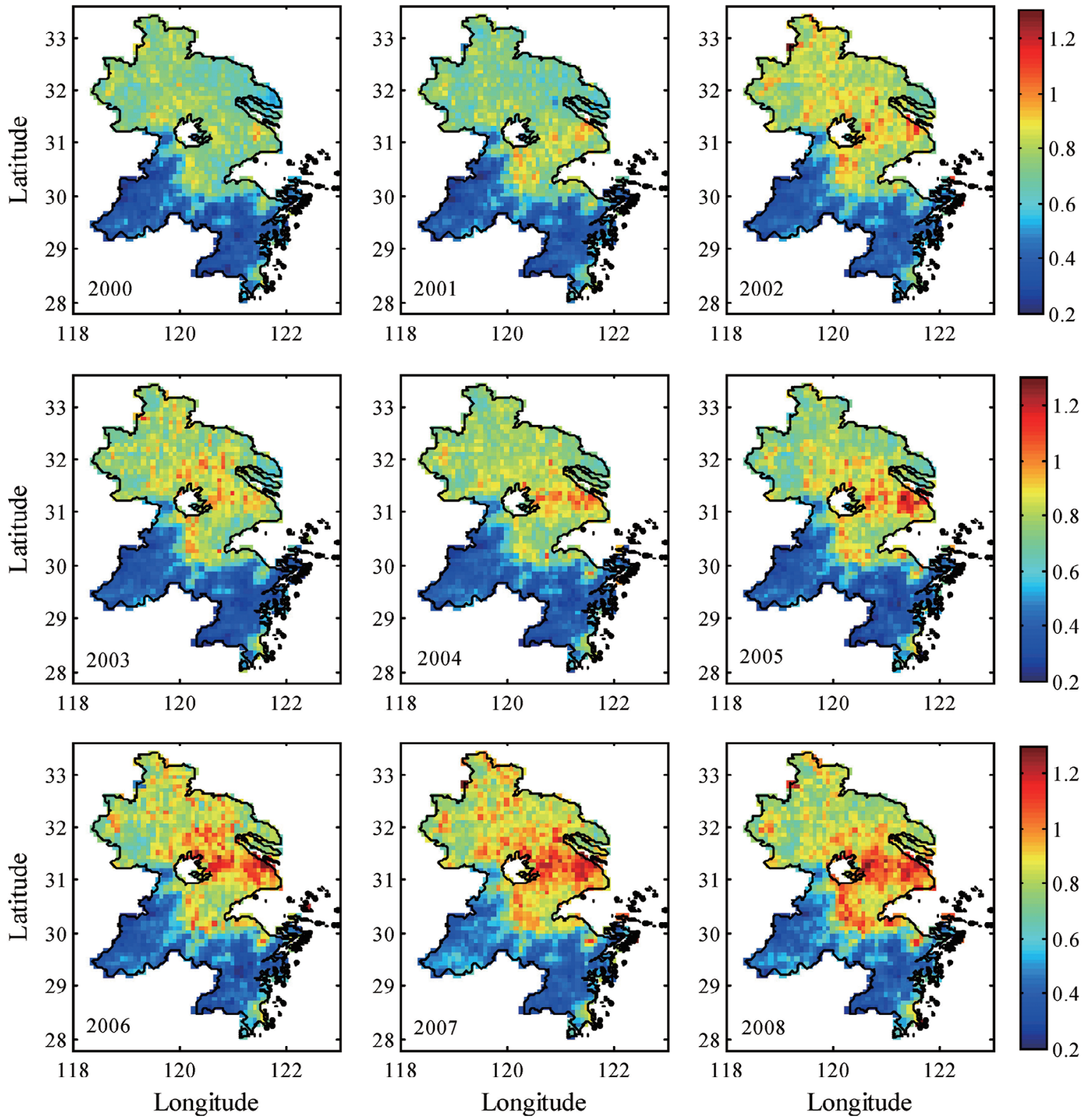

Fig. 8. Spatial distributions of yearly mean AOT from 2000 to 2008 over the Yangtze River Delta.

Table 3. Percentage variations of areas of AOT and NDVI in different ranks in the Yangtze River Delta.

\begin{tabular}{|c|c|c|c|c|c|c|}
\hline Year & AOT $<0.4(\%)$ & NDVI $<0.2(\%)$ & $0.4 \leq \mathrm{AOT} \leq 0.8(\%)$ & $0.2 \leq \mathrm{NDVI} \leq 0.4(\%)$ & $\mathrm{AOT}>0.8(\%)$ & NDVI $\geq 0.4(\%)$ \\
\hline 2000 & 20.8 & 7.04 & 68.59 & 38.99 & 10.61 & 53.97 \\
\hline 2001 & 18.18 & 6.63 & 67.8 & 28.36 & 14.02 & 65.01 \\
\hline 2002 & 16.84 & 6.97 & 46.5 & 26.57 & 36.66 & 66.46 \\
\hline 2003 & 20.78 & 7.25 & 50.35 & 28.43 & 28.88 & 64.32 \\
\hline 2004 & 18.53 & 7.11 & 55.66 & 20.77 & 25.82 & 72.12 \\
\hline 2005 & 19.35 & 7.32 & 49.79 & 21.81 & 30.86 & 70.88 \\
\hline 2006 & 15.18 & 7.66 & 43.94 & 26.02 & 40.89 & 66.32 \\
\hline 2007 & 10.19 & 7.87 & 41.75 & 27.19 & 48.06 & 64.94 \\
\hline
\end{tabular}




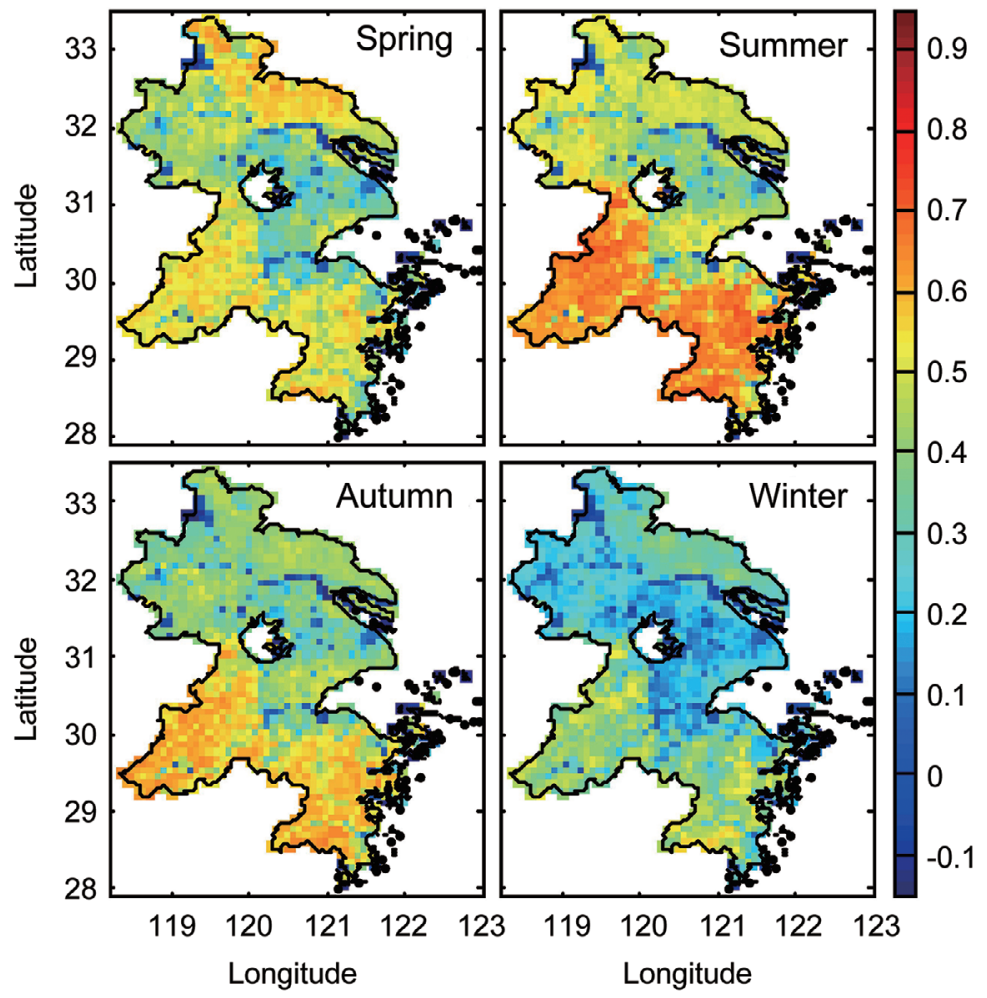

Fig. 9. Spatial distributions of multi-year seasonal mean NDVI from 2000 to 2008 over the Yangtze River Delta.

is primarily deciduous forest. The NDVI in winter is obviously lower when leaves have fallen than other seasons (spring, summer and autumn), and the lowest values appear in the city of Shanghai and the areas around Tai Lake. The NDVI in summer is largest, and the value is up to 0.9 in the south of the YRD region.

Figure 10 and Table 3 indicate that the time series of the areas of different NDVI classes have no explicit trend. The area of NDVI $>0.4$ presents a parabolic variation from 2000 to 2008 . The percentages increase from $53.97 \%$ in 2000 to the peak of $72.12 \%$ in 2004 then decrease to $62.53 \%$ in 2008, while for the areas of NDVI larger than 0.4 the inverse is true. The results suggest that the change of LULC is the source of the NDVI variation, such as urbanization that results in decreasing agricultural land in this region.

\subsubsection{The Relationship of Regional Average AOT with NDVI}

To investigate the relationship between AOT and NDVI, we performed a spatial correlation analysis (pixel to pixel) for the monthly AOT/NDVI over the entire region. The correlation analysis (Fig. 11) produces moderate correlations for aerosol properties and NDVI. The AOT vs. NDVI have a negative correlation range of $0 \sim-0.8$. The correlation results have smaller NDVI values in urban with larger AOT, vice versa. The $\mathrm{R}$ values vary with the seasonal shift with a marked annual cycle. In the period, there are often two peaks and two valleys. The reasons for the correlations are complex. First, the annual periodic variation of NDVI with the influence of solar radiation and the growth of vegetation is significant. Second, the aerosol loading varies with the seasonal changing of complex aerosol components. The variation of NDVI affects which aerosols come into the atmosphere, such as soil dust from surface. In the long term, the correlation of AOT/NDVI is decreasing.

Figure 11 also reveals that the $\mathrm{R}$ values of AOT/NDVI vary with time as the vegetation presents different responses to the seasonal and regional variability of AOT. The correlation of AOT vs. NDVI is moderately negative, and the mean value is about -0.43 in spring, -0.58 in summer, -0.60 in autumn and -0.48 in winter. As shown by Fig. 9, the NDVI values in summer and autumn are larger than those of in spring and winter, in particularly, the NDVI value is large in the southern YRD region. This suggests that AOT is increasing with NDVI decrease. The results of correlations shown in Fig. 11 imply that the AOT values are related to the seasonal variation of NDVI. There is an interaction between aerosol loading and vegetation coverage. Vegetation can reduce the aerosol particles in the atmosphere via the sorption, and on the other hand, aerosol affects the vegetation growth by changing the surface solar radiation such as an increased diffuse radiative flux fraction. This in turn affects the variation in NDVI, implying that there are close relationships for 
AOT and NDVI. With respect to the inter-annual variation, the $\mathrm{R}$ increases with time in spring and summer, while the $\mathrm{R}$ decreases in autumn and winter.

We classified NDVI into two classes according to a regional average value (NDVI $=0.3)$. The value of NDVI $>$ 0.3 represents a densely vegetated area, whereas NDVI $\leq 0.3$ represents sparse vegetation. As shown by Fig. 12, the first group (NDVI $>0.3$ ) produces weak correlations of AOT vs. NDVI ranging from \pm 0.2 . The second group (NDVI $\leq$ 0.3 ) includes moderate negative correlations of AOT and NDVI ranging from -0.2 to -0.8 . The reason for the correlation patterns may in part derive from the role of NDVI as an indicator of human activity. The smaller value of NDVI implies intensive human activity. So the urban/industrial aerosol is high loading in low NDVI region, which makes the AOT large. On the other hand, vegetation can absorb aerosol particles and at the same time, decrease the emission of soil dust. This process removes the aerosol particles from atmosphere in dense vegetation areas, which makes the AOT small. Therefore the relationship of AOT vs. NDVI produces negative correlations, in particular, these negative correlations are more obvious in dense vegetation areas and the correlation varies with the seasonal change of NDVI.

\section{CONCLUSIONS}

The aerosol properties retrieved from MODIS including AOT have been analyzed in this paper, the MODIS L2
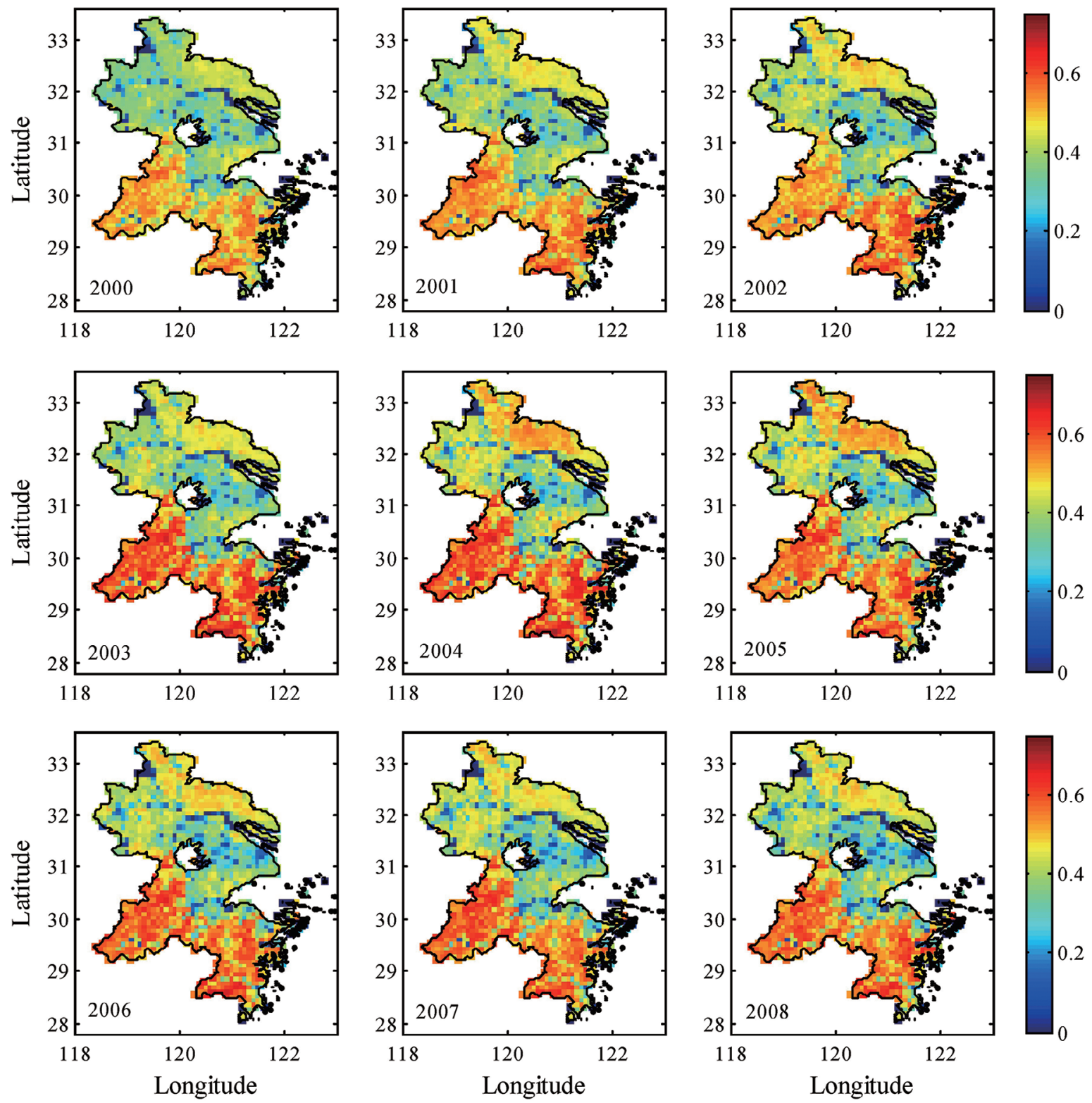

Fig. 10. Spatial distributions of yearly mean NDVI from 2000 to 2008 over the Yangtze River Delta. 


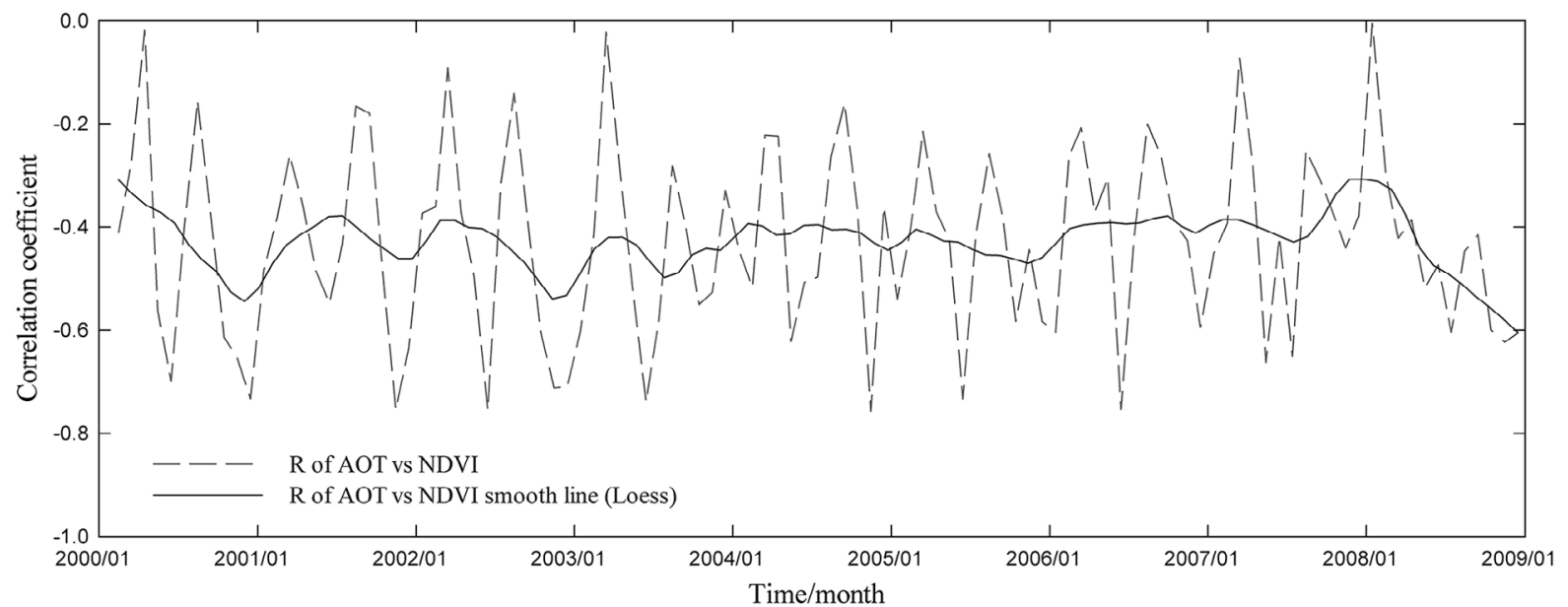

Fig. 11. The dashed line and the solid line are the variation of R of AOT vs. NDVI and its smooth line, respectively.

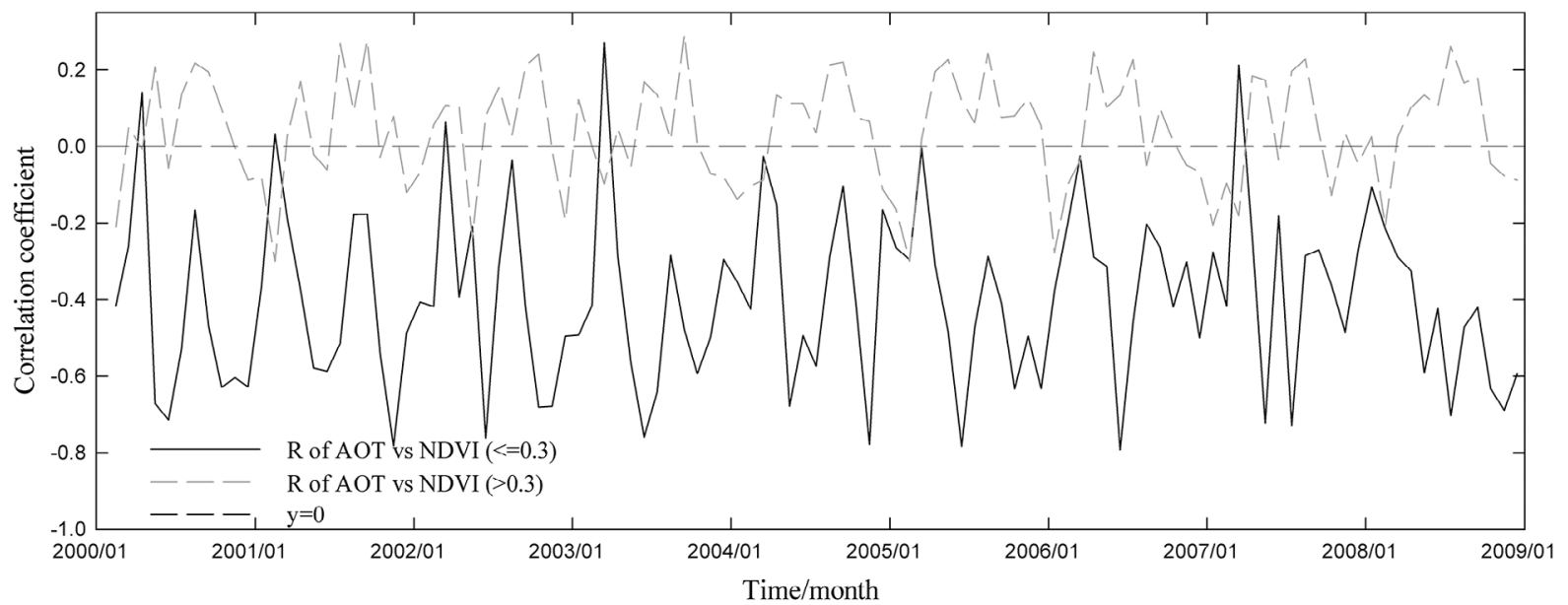

Fig. 12. The dashed line and the solid line are the variation of R of AOT vs. NDVI in different NDVI grades (NDVI $\leq 0.3$ and NDVI $>0.3$ ), respectively.

aerosol product is validated using the ground-based measurement data. The study presents the characteristics of AOT in the Yangtze River Delta (YRD) and the SPOT-VGT NDVI is used for the analysis of the correlation between aerosol properties and NDVI. The validation indicates that the MODIS AOT is in good agreement with ground-based measurements in Hangzhou station, the slope and intercept are 1.04 and -0.01 with R and RMSE equal to 0.92 and 0.20 respectively.

The long term variation of AOT over the YRD is increasing over time, and the regional monthly mean AOT presents annual period variations, and varies with seasonal shift. The largest value of AOT appears in June $(0.95 \pm 0.20$ s.d.). There are two different aerosol modes and present distinctly different spatial patterns. One consists of a smaller AOT over areas with dense vegetation with a natural type of aerosol in Qiandao Lake. The other is a larger AOT over urban areas with an urban/industrial type of aerosol around Tai Lake. The AOT is getting larger over the entire region.

The correlation analysis indicates that there are moderate correlations for AOT and NDVI. AOT vs. NDVI have a negative correlation and the $\mathrm{R}$ values vary with the seasonal shift. The range of $\mathrm{R}$ values is $0 \sim-0.8$, and the mean values are about -0.5 . The variation of $\mathrm{R}$ values presents a marked one year cycle period, due to the vegetation presenting different response to the seasonal and regional variability of AOT. The relationship between AOT and NDVI is more obvious in dense vegetation. The higher $\mathrm{R}$ values of AOT vs. NDVI appear in summer and autumn with -0.58 and -0.60 . In the long term, the correlation of AOT/NDVI decreases due to the decrease of vegetation cover in this region.

Acknowledgements The authors would like to thank NASA/MODIS (http://modis.gsfc.nasa.gov) for providing 
aerosol products. The authors also would like to thank SPOT (http://www.vgt.vito.be) for providing NDVI product. Funding support partially from the Scientific Research Foundation of Jimei University, China, and the NSF China Major Program (61190114 and 41171324), the State Key Fundamental Science Funds of China (2011CB302705, 2010CB950702, and 2010CB428503), the Funds for Ph.D. Education (20110091110028), the State High Technology Funds of China (2009AA122001 and 2009AA122005), the State Key Basic Research Funds of China (2007FY11030004 and 08), the Project Funded by the Priority Academic Program Development of Jiangsu Higher Education Institutions, Zhejiang Province Key Science and Technology Innovation Team (2010R50030).

\section{REFERENCES}

Adamopoulos, A. D., H. D. Kambezidis, D. G. Kaskaoutis, and G. Giavis, 2007: A study of aerosol particle sizes in the atmosphere of Athens, Greece, retrieved from solar spectral measurements. Atmos. Res., 86, 194-206, doi: 10.1016/j.atmosres.2007.04.003. [Link]

Ångström, A., 1929: On the atmospheric transmission of sun radiation and on dust in the air. Geogr. Ann., 11, 156-165.

Cachorro, V. E., P. Durán, R. Vergaz, and A. M. de Frutos, 2000: Columnar physical and radiative properties of atmospheric aerosols in north central Spain. J. Geophys. Res., 105, 7161-7175, doi: 10.1029/1999JD901165. [Link]

Charlson, R. J., J. Langner, H. Rodhe, C. B. Leovy, and S. G. Warren, 1991: Perturbation of the Northern Hemisphere Radiative balance by backscattering from anthropogenic sulfate aerosols. Tellus A, 43, 152-163, doi: 10.1034/j.1600-0870.1991.00013.x. [Link]

Charlson, R. J., S. E. Schwartz, J. M. Hales, R. D. Cess, J. A. Coakley, J. E. Hansen, and D. J. Hofmann, 1992: Climate forcing by anthropogenic aerosols. Science, $\mathbf{2 5 5}$, 423-430, doi: 10.1126/science.255.5043.423. [Link]

Chu, D. A., Y. J. Kaufman, C. Ichoku, L. A. Remer, D. Tanré, and B. N. Holben, 2002: Validation of MODIS aerosol optical depth retrieval over land. Geophys. Res. Lett., 29, MOD2-1-MOD2-4, doi: 10.1029/2001GL013205. [Link]

d'Almeida, G. A., 1987: On the variability of desert aerosol radiative characteristics. J. Geophys. Res., 92, 30173026, doi: 10.1029/JD092iD03p03017. [Link]

Eck, T.F., B. N. Holben, J. S. Reid, O. Dubovik, A. Smirnov, N. T. O'Neill, I. Slutsker, and S. Kinne, 1999: Wavelength dependence of the optical depth of biomass burning, urban, and desert dust aerosols. J. Geophys. Res., 104, 31333-31349, doi: 10.1029/1999JD900923. [Link]

Eck, T. F., B. N. Holben, D. E. Ward, O. Dubovik, J. S. Reid,
A. Smirnov, M. M. Mukelabai, N. C. Hsu, N. T. O’Neil, and I. Slutsker, 2001: Characterization of the optical properties of biomass burning aerosols in Zambia during the 1997 ZIBBEE field campaign. J. Geophys. Res., 106, 3425-3448, doi: 10.1029/2000JD900555. [Link]

Fouquart, Y., B. Bonnel, G. Brogniez, J. C. Buriez, L. Smith, and J. J. Morcrette, 1987: Observations of Saharan aerosols: Results of ECLATS Field experiment. Part II: Broadband radiative characteristics of the aerosols and vertical radiative flux divergence. J. Clim. Appl. Meteorol., 26, 38-52, doi: 10.1175/1520-0450(1987)0 26<0038:OOSARO >2.0.CO;2. [Link]

Haywood, J. and O. Boucher, 2000: Estimates of the direct and indirect radiative forcing due to tropospheric aerosols: A review. Rev. Geophys., 38, 513-543, doi: 10.1029/1999RG000078. [Link]

Holben, B. N., T. F. Eck, I. Slutsker, D. Tanré, J. P. Buis, A. Setzer, E. Vermote, J. A. Reagan, Y. J. Kaufman, T. Nakajima, F. Lavenu, I. Jankowiak, and A. Smirnov, 1998: AERONET - A federated instrument network and data archive for aerosol characterization. Remote Sens. Environ., 66, 1-16, doi: 10.1016/S00344257(98)00031-5. [Link]

Holben, B. N., D. Tanré, A. Smirnov, T. F. Eck, I. Slutsker, N. Abuhassan, W. W. Newcomb, J. S. Schafer, B. Chatenet, F. Lavenu, Y. J. Kaufman, J. Vande Castle, A. Setzer, B. Markham, D. Clark, R. Frouin, R. Halthore, A. Karneli, N. T. O’Neill, C. Pietras, R. T. Pinker, K. Voss, and G. Zibordi, 2001: An emerging groundbased aerosol climatology: Aerosol optical depth from AERONET. J. Geophys. Res., 106, 12067-12097, doi: 10.1029/2001JD900014. [Link]

Ichoku, C., D. A. Chu, S. Mattoo, Y. J. Kaufman, L. A. Remer, D. Tanré, I. Slutsker, and B. N. Holben, 2002: A spatio-temporal approach for global validation and analysis of MODIS aerosol products. Geophys. Res. Lett., 29, MOD1-1-MOD1-4, doi: 10.1029/2001GL013206. [Link]

Ichoku, C., Y. J. Kaufman, L. A. Remer, and R. Levy, 2004: Global aerosol remote sensing from MODIS. $A d v$. SpaceRes.,34,820-827,doi:10.1016/j.asr.2003.07.071. [Link]

IPCC (Intergovernmental Panel on Climate Change), 2001: Climate Change 2001: The Scientific Basis, Cambridge University Press, New York, USA, 881 pp.

IPCC (Intergovernmental Panel on Climate Change), 2007: Climate Change 2007: The Physical Science Basis, Cambridge University Press, New York, USA, 996 pp.

Kaskaoutis, D. G., H. D. Kambezidis, A. D. Adamopoulos, and P. A. Kassomenos, 2006: On the characterization of aerosols using the Angström exponent in the Athens area. J. Atmos. Sol.-Terr. Phys., 68, 2147-2163, doi: 10.1016/j.jastp.2006.07.008. [Link]

Kaufman, Y. J., D. Tanré, L. A. Remer, E. F. Vermote, A. 
Chu, and B. N. Holben, 1997: Operational remote sensing of tropospheric aerosol over land from EOS moderate resolution imaging spectroradiometer. J. Geophys. Res., 102, 17051-17067, doi: 10.1029/96JD03988. [Link]

Kaufman, Y. J., D. Tanré, and O. Boucher, 2002: A satellite view of aerosols in the climate system. Nature, $\mathbf{4 1 9}$, 215-223, doi: 10.1038/nature01091. [Link]

Kim S. W., S. C. Yoon, J. Kim, S. Y. Kim, 2007: Seasonal and monthly variations of columnar aerosol optical properties over east Asia determined from multi-year MODIS, LIDAR, and AERONET Sun/sky radiometer measurements. Atmos. Environ., 41, 1634-1651, doi: 10.1016/j.atmosenv.2006.10.044. [Link]

King, M. D., Y. J. Kaufman, D. Tanré, and T. Nakajima, 1999: Remote sensing of tropospheric aerosols from space: Past, present, and future. Bull. Amer. Meteorol. Soc., 80, 11, 2229-2259, doi: 10.1175/1520-0477(199 9)080<2229:RSOTAF>2.0.CO;2. [Link]

Kosmopoulos, P. G., D. G. Kaskaoutis, P. T. Nastos, and H. D. Kambezidis, 2008: Seasonal variation of columnar aerosol optical properties over Athens, Greece, based on MODIS data. Remote Sens. Environ., 112, 23542366, doi: 10.1016/j.rse.2007.11.006. [Link]

Levy, R. C., L. A. Remer, J. V. Martins, Y. J. Kaufman, A. Plana-Fattori, J. Redemann, and B. Wenny, 2005: Evaluation of the MODIS aerosol retrievals over ocean and land during CLAMS. J. Atmos. Sci., 62, 974-992, doi: 10.1175/JAS3391.1. [Link]

Levy, R. C., L. A. Remer, S. Mattoo, E. F. Vermote, and Y. J. Kaufman, 2007: Second-generation operational algorithm: Retrieval of aerosol properties over land from inversion of Moderate Resolution Imaging Spectroradiometer spectral reflectance. J. Geophys. Res., 112, D13211, doi: 10.1029/2006JD007811. [Link]

Levy, R. C., L. A. Remer, R. G. Kleidman, S. Mattoo, C. Ichoku, R. Kahn, and T. F. Eck, 2010: Global evaluation of the Collection 5 MODIS dark-target aerosol products over land. Atmos. Chem. Phys., 10, 1039910420, doi: 10.5194/acp-10-10399-2010. [Link]

Lyamani, H., F. J. Olmo, A. Alcántara, and L. Alados-Arboledas, 2006: Atmospheric aerosols during the 2003 heat wave in southeastern Spain I: Spectral optical depth. Atmos. Environ., 40, 6453-6464, doi: 10.1016/j. atmosenv.2006.04.048. [Link]

Ramanathan, V., P. J. Crutzen, J. T. Kiehl, and D. Rosenfeld,
2001: Aerosols, climate, and the hydrological cycle. Science, 294, 2119-2124, doi: 10.1126/science.1064034. [Link]

Remer, L. A., Y. J. Kaufman, D. Tanré, S. Mattoo, D. A. Chu, J. V. Martins, R. R. Li, C. Ichoku, R. C. Levy, R. G. Kleidman, T. F. Eck, E. Vermote, and B. N. Holben, 2005: The MODIS aerosol algorithm, products, and validation. J. Atmos. Sci., 62, 947-973, doi: 10.1175/ JAS3385.1. [Link]

Salomonson, V. V., W. Barnes, P. W. Maymon, H. E. Montgomery, and H. Ostrow, 1989: MODIS: advanced facility instrument for studies of the Earth as a system. IEEE Trans. Geosci. Remote Sensing, 27, 145-153, doi: 10.1109/36.20292. [Link]

Smirnov, A., B. N. Holben, O. Dubovik, N. T. O’Neill, T. F. Eck, D. L. Westphal, A. K. Goroch, C. Pietras, and I. Slutsker, 2002: Atmospheric aerosol optical properties in the Persian Gulf. J. Atmos. Sci., 59, 620-634, doi: 1 0.1175/1520-0469(2002)059<0620:AAOPIT>2.0.CO ;2. [Link]

Tanré, D., Y. J. Kaufman, M. Herman, and S. Mattoo, 1997: Remote sensing of aerosol properties over oceans using the MODIS/EOS spectral radiances. J. Geophys. Res., 102, 16971-16988, doi: 10.1029/96JD03437. [Link]

Tucker, C. J., 1979: Red and photographic infrared linear combinations for monitoring vegetation. Remote Sens. Environ., 8, 127-150, doi: 10.1016/0034-4257(79) 90013-0. [Link]

Tucker, C. J., C. L. Vanpraet, M. J. Sharman, and G. Van Ittersum, 1985: Satellite remote sensing of total herbaceous biomass production in the Senegalese Sahel: 1980-1984. Remote Sens. Environ., 17, 233-249, doi: 10.1016/0034-4257(85)90097-5. [Link]

Wang, L. , J. Xin, Y. Wang, Z. Li, G. Liu, and J. Li, 2007: Evaluation of the MODIS aerosol optical depth retrieval over different ecosystems in China during EASTAIRE. Atmos. Environ., 41, 7138-7149, doi: 10.1016/j. atmosenv.2007.05.001. [Link]

Xin, J., Y. Wang, Z. Li, P. Wang, W. M. Hao, B. L. Nordgren, S. Wang, G. Liu, L. Wang, T. Wen, Y. Sun, and B. Hu, 2007: Aerosol optical depth (AOD) and Ångström exponent of aerosols observed by the Chinese Sun Hazemeter Network from August 2004 to September 2005. J. Geophys. Res., 112, D05203, doi: 10.1029/2006JD007075. [Link] 